\title{
Pattern of Occurrence of Leukemia at a Teaching Hospital in Eastern Region of Nepal - A Six Year Study
}

\author{
Kulshrestha R, ${ }^{\prime}$ Sah SP' \\ 'Department of Pathology, B.P. Koirala Institute of Health Sciences, Dharan, Nepal
}

\section{ABSTRACT}

Introduction: Pattern of leukemia is known to vary widely throughout the world. The characterization of distribution patterns of different subtypes of leukemia in Nepal needs further study. We wanted to study the leukemia pattern in our institute.

Methods: A retrospective study of 196 cases of leukemia, diagnosed at BPKIHS, between January 1997 to December 2002 was done. We analyzed the pattern of leukemia at BPKIHS by morphological subtype, gender, age at diagnosis, time period of diagnosis (seasonality), and geographic distribution.

Results: Morphological sub typing showed that 121 cases were of acute leukemia and 75 of chronic leukemia. Chronic myeloid leukemia constituted the single largest group comprising $35.2 \%$ of all cases, followed by acute myeloid leukemia (28.57 \%) and acute lymphoid leukemia (19.9 \%). Maximum numbers of cases were from the lowlands while least number of cases were from the mountain districts. Results were compared with literature from Nepal and other countries. This is the second series of leukemia from Nepal.

Conclusions: The data published in this study reflects the leukemia pattern in the eastern region of Nepal. The pattern and distribution of AML, CML, ALL was similar to that in the developed western countries while the lesser frequency of CLL was similar to that in Southeast Asian region.

Key Words: leukemia, pattern, eastern Nepal, seasonality.

\section{INTRODUCTION}

Leukemia is malignant neoplasm of the hematopoietic stem cells characterized by diffuse replacement of the bone marrow and/or peripheral blood by neoplastic cells. It was identified as a separate malignancy in 1889. Since then apart from its etiopathogenesis increasing interest has been developing in the geographic pattern of leukemia and its distribution throughout the world.
The observed geographic variation in incidence remains unexplained as yet. Previous studies have shown important differences in geographic, racial/ ethnic, age and trend patterns for different leukemia subtypes. ${ }^{2}$ Thus, suggesting that subtypes may have different etiologic factors. Therefore a comprehensive assessment of leukemia patterns is warranted globally. This paper deals with the study conducted at the B. P. Koirala Institute of Health Sciences, Dharan, Nepal. 
Kulshrestha et al. Pattern of Occurrence of Leukemia at A Teaching Hospital in Eastern Region of Nepal - A Six Year Study

It presents the clinico-pathological profile of patients with leukemia presenting to BPKIHS and reflects the leukemia pattern in the eastern region of Nepal from where no such data has been published till date.

\section{METHODS}

A retrospective study of one hundred and ninety six cases of leukemia diagnosed in the department of Pathology, BPKIHS, from January 1997 to December 2002 was done. In all cases two slides of bone marrow aspiration and one peripheral smear were stained with Jenner's Giemsa. Sudan black and periodic acid Schiff (PAS) and non specific esterase (NSE) were used for identifying and subtyping the myeloid and lymphoid series cells wherever applicable.

Pattern of leukemia at BPKIHS was analyzed by, morphological subtype, gender, age at diagnosis, time period of diagnosis (Seasonality), and geographic distribution. Morphological subtyping was done according to the French-American-British (FAB) classification using morphologic and cytochemical criteria to characterize the blast cells. ${ }^{3}$ The distribution of cases of leukemia was studied in adults and children and according to gender. The time of initial diagnosis of each case was also recorded to assess for seasonal variation in the occurrence of this disease. Cases were distributed according to different geographic areas of Nepal from where they originally came from. ${ }^{4}$

\section{RESULTS}

Of the 196 cases diagnosed 121 cases were of acute leukemia and 75 of chronic leukemia (Table 1). Amongst the acute leukemia, there was preponderance of acute myeloid leukemia 56 cases $(28.57 \%)$ with acute lymphoblastic leukemia 39cases (19.9\%) following it. Nineteen cases $(9.69 \%)$ were of non-Hodgkin's lymphoma with spillover in the peripheral blood (Leukemia phase). Undifferentiated leukemia constituted 7 cases $(3.57 \%)$. Of 75 cases of chronic leukemia, 69 were of chronic myeloid leukemia $(35.20 \%)$ and 6 of chronic lymphocytic leukemia (3.06\%).

Distribution of cases in male and female were analyzed (Table 2). In acute leukemia (121 cases), 71 were male and 50 female, with $M$ : $F$ ratio of $1.42: 1$. While in the chronic leukemia, 55 were male and 20 cases were seen in female and the $M: F$ ratio was 2.72:1. All cases of CLL were found in male. The overall $M$ : $F$ ratio was 1.8:1.

In our series we had a spectrum of patients ranging from 11 days (congenital leukemia) to 81 years of age (AML - $M_{2}$ type). Varying degree of distribution of cases of leukemia in adults and children were seen (Table 3,4). In adults CML $(63 / 148 ; 42.6 \%)$ was commonest type of leukemia followed by AML (45/148; 30.4\%) while CLL was least common $(6 / 148 ; 4 \%)$. ALL accounted for $(17 / 148$ cases; $11.5 \%)$, NHL spillover for $13 / 148$ cases $(8.8 \%)$ and undifferentiated leukemia for $4 / 148$ cases (2.7\%).In children ALL (22/48) $45.83 \%$ was commonest type of leukemia followed by $\mathrm{NHL}$ spillover and AML, both with $11 / 48$ cases (22.92\%) each. Three cases $(6.25 \%)$ were of undifferentiated leukemia. CML constituted $6 / 48$ cases $(12.5 \%)$.

FAB classification was followed to subtype acute leukemia (Table 5). Of the myeloid leukemia, AML $M_{2}$ with $30 / 56$ cases $(53.57 \%)$ was the commonest type, followed by 13 cases $(23.21 \%)$ of AML- $M_{3}$. AML $-M_{1}, M_{5}, M_{4}$, and $M 6$ comprised 5,4,3,1 cases respectively. No case of $A M L-M_{0}, M_{7}$ was diagnosed. ALL- $L_{2}$ subtype with $23 / 39$ cases $(58.97 \%$ ) was the commonest of acute lymphoid leukemia. ALL-L, constituted 15 of 39 cases $(38.46 \%)$ and $A L L-L_{3} 1 / 39$ cases $(2.56 \%)$.

In order to study the seasonal variation in the occurrence of leukemia the distribution of leukemia cases according to the time of initial diagnosis of each case was done (Table 6). The maximum number of cases were in spring (March, April, May and summer (June, July, and August) that is 69 and 51 cases respectively. This was followed by 39 cases in winter (December, January and February) and 37 cases in autumn (September, October and November).

Cases were distributed according to different geographic areas from where they originally came from. It was seen that 142 cases $(72.45 \%)$ were from eastern region of Nepal and 54 cases $(27.55 \%)$ were from the neighboring Indian state of Bihar (Table 7). Among the cases from Nepal maximum cases (112 of 196 cases; $57.14 \%)$ were from terai districts of Jhapa, Morang and Sunsari (Lowlands) followed by cases from hill districts of Bhojpur, Terahthum and Panchthar (27/196; $13.78 \%$ ). Least number of cases (3 cases; $1.53 \%$ ) were from mountain district (Taplejung).

\section{DISCUSSION}

The geographic pattern of leukemia is known to vary widely however this observed geographic variation remains unexplained. Different leukemia subtypes have shown important differences in geographic, racial/ ethnic, age and trend patterns in previous studies thus suggesting that different subtypes may have different etiologic factors. ${ }^{2}$ Therefore a comprehensive assessment of leukemia patterns is warranted globally.

To assess the leukemia pattern in the eastern region of Nepal, we analyzed 196 cases of leukemia diagnosed at BPKIHS over six year period from January 1997 to December 2002. The overall adult on to child ratio 
Kulshrestha et al. Pattern of Occurrence of Leukemia at A Teaching Hospital in Eastern Region of Nepal - A Six Year Study

Table 1. Type of Leukemia

\begin{tabular}{lll}
\hline Type & Total Number & Percentage \\
\hline Acute Leukemia & & \\
AML & 56 & 28.57 \\
ALL & 39 & 19.90 \\
$\begin{array}{l}\text { Undifferentiated } \\
\text { Leukemia }\end{array}$ & 7 & 3.57 \\
NHL spillover & 19 & 9.69 \\
TOTAL & 121 & 61.73 \\
Chronic Leukemia & & \\
CML & 69 & 35.20 \\
CLL & 6 & 3.06 \\
TOTAL & 75 & 38.27 \\
\hline
\end{tabular}

AML: acute myeloidleukemia;ALL: acutelymphoblastic leukemia; UL: undifferentiated leukemia; NHL: nonHodgkin's lymphoma; CML: chronic myelogenous leukemia; CLL: chronic lymphocytic leukemia.

Table 2. Male:Female ratio

\begin{tabular}{lcc}
\hline Type & Male & Female \\
Acute Leukemia & & \\
AML & 29 & 27 \\
ALL & 23 & 16 \\
UL & 5 & 2 \\
NHL spillover & 14 & 5 \\
TOTAL & 71 & 50 \\
Chronic Leukemia & & \\
CML & 49 & 20 \\
CLL & 6 & 0 \\
TOTAL & 55 & 20 \\
\hline
\end{tabular}

AML: acutemyeloidleukemia; ALL: acutelymphoblastic leukemia; UL: undifferentiated leukemia; NHL: nonHodgkin's lymphoma; CML: chronic myelogenous leukemia; CLL: chronic lymphocytic leukemia.

was (148/48) 3.08: 1 and there was an overall male preponderance with Male is to female ratio of 1.8: 1 (126: 70). Patient age ranged from 11 day old to 81 years. Morphological sub typing showed that 121 cases $(61.73 \%)$ were of acute leukemia and 75 cases (38.27\%) of chronic leukemia. Chronic myeloid leukemia constituted the single largest group comprising $35.2 \%$ of all cases, followed by acute myeloid leukemia $(28.57$ $\%)$ and acute lymphoid leukemia (19.9\%).

$\mathrm{CML}$, a clonal stem cell disorder characterized by increased proliferation of myeloid elements at all stages of differentiation, is principally a disease of adults ${ }^{5}$ and accounts for less than $5 \%$ of all childhood leukemias. ${ }^{6}$
Table 3. Leukemia in Adults $(\mathbf{N}=148)$

\begin{tabular}{lcc}
\hline Type & Cases & Percentage \\
\hline Acute Leukemia & & \\
AML & 45 & 30.4 \\
ALL & 17 & 11.5 \\
UL & 4 & 2.7 \\
NHL spillover & 13 & 8.8 \\
TOTAL & 79 & \\
Chronic Leukemia & & \\
CML & 63 & 42.6 \\
CLL & 6 & 4.0 \\
TOTAL & 69 & \\
\hline
\end{tabular}

AML: acute myeloidleukemia; ALL: acutelymphoblastic leukemia; UL: undifferentiated leukemia; NHL: nonHodgkin's lymphoma; CML: chronic myelogenous leukemia; CLL: chronic lymphocytic leukemia.

Table 4. Leukemia in Children $(\mathbf{N}=\mathbf{4 8})$

\begin{tabular}{lll}
\hline Type & Cases & Percentage \\
\hline Acute Leukemia & 11 & 22.92 \\
AML & 22 & 45.83 \\
ALL & 3 & 6.25 \\
UL & 11 & 22.92 \\
NHL spillover & 42 & 87.5 \\
TOTAL & & \\
Chronic Leukemia & 6 & 12.5 \\
CML & 0 & 0 \\
CLL & 6 & 12.5 \\
TOTAL & & \\
\hline
\end{tabular}

AML: acute myeloid leukemia; ALL: acutelymphoblastic leukemia; UL: undifferentiated leukemia; NHL: nonHodgkin's lymphoma; CML: chronic myelogenous leukemia; CLL: chronic lymphocytic leukemia.

In present study, CML accounted for (63/148) 42.6 $\%$ of adult and $6 / 48(12.5 \%)$ of childhood leukemia. A male preponderance seen in this study is similar to reports in literature. ${ }^{7}$ Most of the patients of $\mathrm{CML}$ presented in the chronic phase, however there were some interesting presentations too. One case of $\mathrm{CML}$ showed coexistent infection with Kala-azar. ${ }^{8}$ One case had second primary choriocarcinoma of ovary with metastasis in the uterus.

Acute myeloid leukemia was second commonest leukemia in the present series. The youngest case was an 11 day old male child (congenital leukemia) and the oldest case was 81 years old female. The single case of 
Kulshrestha et al. Pattern of Occurrence of Leukemia at A Teaching Hospital in Eastern Region of Nepal - A Six Year Study

Table 5. Distribution of Acute Leukemia (FAB Classification)

\begin{tabular}{lcc}
\hline \multicolumn{1}{c}{$\begin{array}{c}\text { Type of } \\
\text { Leukemia }\end{array}$} & $\begin{array}{c}\text { No of Cases } \\
(\mathbf{n}=95)\end{array}$ & Percentage \\
\hline Acute & Myeloid Leukemia $(\mathrm{n}=56)$ & \\
$\mathrm{M}_{1}$ & 5 & 8.93 \\
$\mathrm{M}_{2}$ & 30 & 53.57 \\
$\mathrm{M}_{3}$ & 13 & 23.21 \\
$\mathrm{M}_{4}$ & 3 & 5.36 \\
$\mathrm{M}_{5}$ & 4 & 7.14 \\
$\mathrm{M}_{6}$ & 1 & 1.79 \\
$\mathrm{M}_{7}$ & $0-$ & 0 \\
$\mathrm{Acute}_{2}$ & Lymphoid Leukemia $(\mathrm{n}=39)$ & \\
$\mathrm{L}_{1}$ & 15 & 38.46 \\
$\mathrm{~L}_{2}$ & 23 & 58.97 \\
$\mathrm{~L}_{3}$ & 1 & 2.56 \\
\hline
\end{tabular}

Table 6. Monthwise Distribution Of Leukemia

\begin{tabular}{llllllll}
\hline Month & 1997 & 1998 & 1999 & 2000 & 2001 & 2002 & Total \\
\hline JAN & 2 & 2 & 1 & 2 & 5 & 4 & 16 \\
FEB & 3 & 2 & 1 & 2 & 4 & 2 & 14 \\
MAR & 3 & 1 & 5 & 0 & 5 & 5 & 19 \\
APR & 7 & 3 & 3 & 6 & 2 & 4 & 25 \\
MAY & 5 & 3 & 2 & 1 & 5 & 9 & 25 \\
JUN & 2 & 2 & 2 & 3 & 3 & 8 & 20 \\
JUL & 1 & 2 & 1 & 1 & 4 & 8 & 17 \\
AUG & 2 & 1 & 2 & 1 & 5 & 3 & 14 \\
SEP & 0 & 3 & 0 & 1 & 2 & 3 & 9 \\
OCT & 1 & 2 & 5 & 0 & 2 & 1 & 11 \\
NOV & 1 & 7 & 2 & 1 & 6 & 0 & 17 \\
DEC & 0 & 3 & 2 & 2 & 0 & 2 & 9 \\
TOTAL & 27 & 31 & 26 & 20 & 43 & 49 & 196 \\
\hline
\end{tabular}

Table 7. Geographic Distribution

\begin{tabular}{lll}
\hline & No of cases & Percentage \\
\hline Eastern region of Nepal & & \\
Terai (Low lands) & 112 & 57.14 \\
Hills & 27 & 13.78 \\
Mountains & 3 & 1.53 \\
INDIA (Bihar) & 54 & 27.55 \\
\hline
\end{tabular}

congenital leukemia had AML with associated Down's syndrome, which is the most common chromosomal anomaly associated with congenital leukemia. ${ }^{9}$ Sub typing according to $F A B$ classification showed AML-M and $M_{3}$ to comprise the highest proportion of cases of $A M L$. Unusual presenting features in $A M L-M_{2}$, were of bilateral parotid involvement in three cases and eye involvement with leukemia cells in three cases. Disseminated intravascular coagulopathy was the most common presenting feature in $A M L-M_{3}$.

Acute lymphoid leukemia is the most common malignant disease, affecting children and accounts for approximately $30 \%$ of childhood cancers. ${ }^{10}$ In present study too, ALL formed the commonest type in children, (22/48) $45.83 \%$ cases. FAB sub typing showed a higher percentage of ALL- $L_{1}$ subtype in children and $L_{2}$ subtype in adults. This is similar to earlier reports in the literature. ${ }^{11}$

In western countries CLL is the most common type of adult leukemia, while decreased incidence of CLL in Asians has been reported. ${ }^{12}$ The basis for this ethnic and geographic variation is unknown. In the present study CLL comprised 6/198 (3.06\%) of all cases. All cases of CLL were in males. This is consistent with reports of male preponderance in CLL in the literature. ${ }^{13}$ Role of genetic and other environmental factors in decreasing CLL risk are suggested. However this subtype specific characteristic of low rate and declining incidence of CLL among Asians warrants further investigation. ${ }^{14}$

Lymphomas represent approximately $10 \%$ of all childhood cancers and are $3^{\text {rd }}$ in relative frequency after leukemia and brain tumors. ${ }^{15}$ The incidence of non-Hodgkin's lymphoma is steadily increasing and it is now emerging as an epidemic worldwide. ${ }^{16}$ In present study non-Hodgkin's lymphoma with spillover into the peripheral blood constituted $13 / 148(8.8 \%)$ of cases of adult leukemia and $11 / 48(22.92 \%)$ of childhood leukemia. Undifferentiated leukemia accounted for (7/198) $3.57 \%$ of acute leukemia. These were the cases, which could not be subtyped on the basis of morphology, and special cytochemical stains alone, as facility for immunocytochemistry was not available.

Literature on seasonality of leukemia has shown conflicting results. Some studies have shown significant summer excess for acute lymphoblastic leukemia at all ages suggestive of a seasonal rhythm of onset. ${ }^{17}$ Other studies have found no evidence of seasonality in the diagnosis. ${ }^{18}$ Infection is a possible etiology factor in leukemia and may vary with season. Seasonal variation in the onset of disease would provide evidence of infectious etiology. There have been various reports from Asian subcontinent regarding a seasonal rise in incidence of leukemia during the start of spring onto the end of monsoons. ${ }^{19,20}$ Therefore we investigated for evidence of seasonality in diagnosis of leukemias by studying the month wise distribution of leukemia cases. Maximum numbers of cases were in spring (March, April, and May) 69 cases and summer (June, July, and August) 51 cases. This was followed by 39 cases in winter (Dec, Jan, and Feb) and 37 cases in autumn 
Kulshrestha et al. Pattern of Occurrence of Leukemia at A Teaching Hospital in Eastern Region of Nepal - A Six Year Study

Table 8. Comparison with World Data

\begin{tabular}{|c|c|c|c|c|}
\hline COUNTRY & AML(\%) & CML(\%) & $\operatorname{ALL}(\%)$ & CLL(\%) \\
\hline NEPAL(BPKIHS, 2003) & 28.57 & 35.20 & 19.90 & 3.06 \\
\hline NEPAL ${ }^{21}$ (TUTH, 1993) & 33 & 29.5 & 25.5 & 0 \\
\hline INDIA $^{22}(1989)$ & 21.9 & 38.4 & 35.95 & 2.89 \\
\hline INDIA $^{23}$ (LNJP, 1982) & 29.7 & 45.4 & 19.3 & 5.71 \\
\hline PAKISTAN $^{24}$ (RMC, 1997) & AL-62.8\% & CL-37.2\% & - & - \\
\hline KUWAIT $^{25}$ (1994) & 32.4 & 14.8 & 44.2 & 8.6 \\
\hline RIYADH $^{26}$ (CENTRAL HOSPITAL, 1991) & 37.54 & 19.11 & 24.23 & 18.77 \\
\hline AFRICA $^{27}(1984)$ & 28.7 & 30.13 & 29.42 & 21.23 \\
\hline DENMARK $^{28}$ (1983) & $A L-40$ & 20 & - & 40 \\
\hline POLAND $^{29}$ (1994) & $A L-50$ & 15 & UL-10 & 25 \\
\hline
\end{tabular}

AML: acute myeloid leukemia; ALL: acute lymphoblastic leukemia; UL: undifferentiated leukemia; NHL: nonHodgkin's lymphoma; CML: chronic myelogenous leukemia; CLL: chronic lymphocytic leukemia.

(Sept, Oct, Nov). Further work in this area is justified.

A distinct geographic pattern in the distribution of cases of leukemia, diagnosed in our hospital was seen. Maximum numbers of cases were from the terai or lowland areas followed by hill areas while least number of cases was from the high mountain areas in this eastern region of Nepal. Factors influencing the lower prevalence of leukemia in the high mountain are also include lower population density in this region and lower socioeconomic status of this population, who were therefore not able to avail the medical facilities.

Pattern of leukemia seen in this study was compared to one previous study from Central region of Nepal (the Kathmandu valley) and other studies from world literature. CML (35.20\%) followed by AML (28.57\%) was the commonest type of leukemia in our study. Previous study from TUTH, Nepal found AML (33.0\%) followed by CML $(29.5 \%)$ to be the commonest type of leukemia. ${ }^{21}$

In Southeast Asian region it was seen that the pattern of higher incidence of myeloid type of leukemia ( $A M L$ and $\mathrm{CML}$ ) emerging from Nepal was similar to two studies from India (Table 8). ${ }^{22,23}$ Higher incidence of acute leukemia $(61.3 \%)$ as compared to chronic leukemia $(38.27 \%)$ in present study was similar to one report from Pakistan $\left(62.8 \%\right.$ and $37.2 \%$ respectively).$^{24}$ CLL was the least common type of leukemia in present study. This low incidence of CLL found in our series is similar to the low incidence found in other study from Nepal and other countries of South east Asian region where it accounted for 0 to $5.71 \%$ cases. ${ }^{21-24}$

In the Middle East region, ALL was the commonest type of leukemia in one study from Kuwait while AML was commonest type of leukemia in study from Riyadh. ${ }^{25,26}$ However; CLL was much commoner and accounted for $8.6 \%$ and $18.77 \%$ cases in the two studies respectively.

Reports from various parts of Africa have documented frequent occurrence of chronic lymphocytic leukemia, predominantly in women, below the age of 50 years suggestive of a role for the influence of life style in leukaemogenesis. ${ }^{27}$ In data from European countries the occurrence of chronic lymphocytic leukemia was seen to vary up to $40 \%$. $^{28,29}$

Thus the pattern and distribution of $A M L, C M L, A L L$ in the present study is similar to that in the developed western countries while the lesser frequency of CLL is similar to that in the Southeast Asian region. The subtype specific characteristics, geographic variation and time trends seen in this study warrant further investigations and comprehensive assessment. From Nepal there is scarcity of data on the pattern of leukemia and this has prompted the presentation of this study, which is the first from the eastern region of Nepal. 


\section{REFERENCES}

1. Ebstein W: Uber die acute leukemie and pseudoleukamie. Dtsch Arch Klin Med 44: 343, 1889.

2. Groves FD, Linet MS, Devesa SS. Patterns of occurrence of the leukemias. Comment in : Eur J Cancer 1995; 31A: 941-9.

3. Bennett JM, Catovsky D, Dainel MT, et al. Proposal for the recognition of minimally differentiated acute myeloid leukemia (AML - Mo). Br J Hematol 1991; 78: 325 - 329.

4. Singh M.L. Population distribution and growth. In: Population monograph of Nepal. Central Bureau of Statistics, Kathmandu, Nepal, 1995 pp 25-59.

5. Kantarjian HM, Talpaz M, Gutterman JU. Chronic myelogenous leukemia. Past, Present and future. Hematol Pathol 1988; 2: 91 - 120.

6. Rowe JM, Lichtman MA, Hyperleukocytosis and leukostasis: Common features of childhood chronic myelogenous leukemia. Blood 1984; 63: 1230 - 4 .

7. Moloney WC. Natural history of chronic granulocytic leukemia. Clin Haematol 1977; 6: 41 - 53.

8. Sah SP, Rijal S, Bhadani PP, Rani S, Koirala S. Visceral leishmaniasis in two cases of leukemia. Southeast Asian J Trop Med Pub Health 2002; 33:25-7.

9. Verma M, Rawat P, Das S, Kakkar N, Sohi I. Congenital acute myeloid leukemia in a case of Down's syndrome-a case report. Indian J Hemat and Blood Transf. 2001; 19: 110-11.

10. Young $\mathrm{YL}$, Miller RW. Incidence of malignant tumors in children. J Pediatr 1975; 86: 254 - 8.

11. Baccarani M, Corbelli G, Amadori S, et al. Adolescent and adult acute lymphoblastic leukemia. Prognostic features and outcome of therapy. A study of 293 patients. Blood 1982; 60: $677-84$

12. Singh T, Basu D, Prakash S, Rani S, Gaiha M. Marrow histomorphology and clinical staging of chronic lymphocytic leukemia- a rare disease in India: experience with 26 cases. Leuk Lymph 1993; 10; 117-19.

13. Dighiero G, Travade $P$, Cheuret $S$, et al and the French co-operative Group on CLL. B cell chronic lymphocytic leukemia: Present status and future directions. Blood 1991; 78: $1901-14$.

14. Gale RP, Cozen W, Goodman MT, Wang FF, Bernstein L. Decreased chronic lymphocytic leukemia incidence in Asians in Los Angeles County. Leuk Res 2000; 24: 665-9.
15. G. Richard Lee, Foerster J, Lukens J, Paraskenes F, Geer JP, Rodgers GM. Non-Hodgkins lymphoma. Chapter 95. In: Wintrobe's clinical Hematology Volume 2. 10th ed. Edited by; Greer J.P, Macon W. R, Mc Curley TL. Williams \& Wilkins. pg $2447-2537$.

16. Palackdharry CS. The epidemiology of non-Hodgkins lymphoma: Why the increased incidence? Oncology 1994; 8: 67-73.

17. Badrinath P, Day NE, Stockton D. Seasonality in the diagnosis of acute lymphocytic leukemia. Br J Cancer 1997; 75 :1711-3.

18. Douglas S, Cortina-Borja M, Cartwright R. A quest for seasonality in presentation of leukemia and non-Hodgkin's lymphoma. Leuk Lymphoma 1999; 32(5-6) 523-32.

19. Kushwaha MRS, Bagchi M, Mehrotra RML. Leukemia at Lucknow- a study of 200 cases. Ind J Cancer 1978; 15; 28-34.

20. Menezes S, Malik GB. A study of leukemia in Goa. Indian J Pathol Microbiol 1977; 20, 83-90.

21. Hamal P. Leukemias in TU teaching hospital. A 8 year 4 month study. J Nep Med Assoc 1993; 31: 368 - 381.

22. D' Costa G, Siddiqui HM, Pradhan RM, Gupte SS. Pattern of leukemias: a ten year incidence study of 242 cases. J Post grad Med 1989; 35; 191-5.

23. Sudha Rani, Beohar PC, Mohanty TK, Mathur MD. Leukemia pattern in Delhi - a ten-year study of 490 cases. Indian J Cancer 1982; 19:81-86.

24. Hassan K, Ikram N, Shah SH. A morphological pattern of 234 cases of leukemias. J Pak Med Assoc 1994; 44: 145-8.

25. Al-Bahar S, Pardita R, al - Muhannaha A, al-Bahar E. The epidemiology of leukemia in Kuwait. Leuk Res 1994; 18: 299 $-307$.

26. Khan MQ, Shivarudrappa AS, al-Bialy S, al-Khawagi MZ, al-Mofarreh M. Leukemia cases in central hospital, Riyadh (Saudi Arabia) J Indian Med Assoc 1991; 89: 38 - 42.

27. Williams C.K. Some biological and epidemiological characteristics of human leukemia in Africans. IARC Sci Publ $1984 ; 687-712$.

28. Hansen NE Karle H, Jensen OM. Trends in the incidence of leukemia in Denmark, 1943 - 77: an epidemiologic study of 14,000 patients. J Natt Cancer Inst 1983; 71: 697 - 701.

29. Kwiatkowski A. Trends in the incidence of leukemia in Poland (1963-90): an epidemiologic study. Eur J Cancer Prev 1994; $3: 277-83$. 